\title{
LA VISIÓN TURCA DE LAS CARTAS DESDE ESTAMBUL DE LADY MONTAGU
}

\author{
MARÍA JESÚS HORTA \\ Universidad de Estambul \\ hortamj@istanbul.edu.tr \\ ORCID: 0000-0002-4146-005X
}

\section{RESUMEN}

Las Cartas desde Estambul de lady Mary Montagu constituyen una de las primeras obras occidentales que ofrecen una visión realista de los turcos del siglo XVIII a través de una óptica femenina. Escritas durante su viaje de ida y vuelta y a lo largo de una estancia de poco más de un año en el Imperio Otomano, en ellas lady Montagu se muestra como una dama curiosa e interesada por descubrir la verdadera realidad del «Otro», algo poco habitual hasta entonces. Por otra parte, su condición de esposa del embajador británico le permitió acceder a espacios vedados hasta entonces a los visitantes varones. Este artículo se centra en ofrecer la visión que los académicos turcos actuales tienen de las Cartas y de su autora, la forma en que valoran sus comentarios y qué tipo de opiniones les merecen el personaje y sus observaciones.

PALABRAS CLAVE: Imperio Otomano, siglo XVIII, visión del Otro, lady Montagu, Cartas desde Estambul.

\section{LADY MONTAGU'S EMBASSY TO CONSTANTINOPLE AS VIEWED BY TURKISH SCHOLARS}

ABSTRACT

Lady Mary Montagu's Embassy to Constantinople is one of the first Western works to offer a realistic view of the 18th century Turks through a female perspective. Written during her round trip and stay of just over a year in the Ottoman Empire, in her letters Lady Montagu appears as an inquisitive lady interested in discovering the true reality of the "Other", something unusual until then. On the other hand, her status as the wife of the British ambassador allowed her to access spaces that were previously forbidden to male visitors. This article focuses on the view that current Turkish scholars have of the Letters and their author, how they value their comments and what kind of opinions the character and their observations deserve.

KEYWORDS: Ottoman Empire, 18th century, view of the "Other", Lady Montagu, Embassy to Constantinople.

\section{LADY MONTAGU Y SU VIAJE AL IMPERIO OTOMANO}

Lady Mary Wortley Montagu (1689-1762) fue la primogénita de sir John Evelyn Pierrepoint, con posterioridad lord Kingston. Su niñez y juventud transcurrieron entre la casa paterna en Londres y la impresionante mansión de Thoresby Hall en Nottinghamshire. Desde muy pronto fue consciente de que la educación habitual que en esa época recibían las damas nobles inglesas resultaba 
insuficiente y, por ese motivo, decidió completarla por sí misma aprendiendo latín, arte y literatura. Para lograrlo, aprovechó la biblioteca de la familia (Murphy 1988: 10) y el contacto con los numerosos huéspedes ilustres que visitaban la casa familiar. Realizó igualmente algunos viajes por Francia e Italia que le ayudaron a ampliar sus conocimientos. Gracias a ese esfuerzo pronto tuvo la posibilidad de acceder a un círculo intelectual prestigioso compuesto por poetas, dramaturgos, estadistas, filósofos... Durante toda su vida nunca perdió su interés por aprender, algo que podemos observar con claridad en sus Cartas.

En su adolescencia compuso algunos poemas alegóricos y durante toda su vida acostumbró a llevar un registro de sus actividades y pensamientos (aunque en algunas de sus Cartas [XI, 48 $]^{1}$ niegue, de manera retórica, su gusto por escribir). De ahí que no deba extrañarnos su interés por transmitir todo lo descubierto en su viaje a Oriente: probablemente lo hizo no solo para ilustrar a sus corresponsales sino como forma también de conservar ella misma esos recuerdos. Tal vez por eso guardó copia de todas las cartas que fue enviando a parientes y amigos.

En 1708 conoció a Edward Wortley Montagu, hijo del conde de Sandwich, el cual, tras recibir una esmerada instrucción en el Trinity College de Cambridge, había ingresado en el parlamento y se había convertido también en un exitoso hombre de negocios (Murphy 1988: 13). Pero las negociaciones para el matrimonio de ambos jóvenes se encallaron. Finalmente, lady Mary tomó la decisión de casarse en 1712 sin el consentimiento paterno y, por tanto, sin ningún tipo de dote, lo que la dejó en una situación económica totalmente dependiente de su marido (Murphy 1988: 14-19). Poco después de dar a luz a su primogénito, lady Mary contrajo la viruela y quedó físicamente marcada de por vida.

En abril de 1716 lord Montagu fue designado embajador ante la Sublime Puerta por cinco años con el objetivo principal de lograr la paz entre el Imperio Austriaco y el Otomano, en guerra desde 1714. Los británicos, que se habían convertido en aliados de los Habsburgo durante la guerra de sucesión española (1702-13) y el Tratado de Utrecht (1713-5), acababan de establecer relaciones diplomáticas firmes con el Imperio Otomano (vid. infra) y pretendían alcanzar un triple objetivo: debilitar la influencia francesa entre los otomanos, contrarrestar el empuje ruso en Asia y oponerse a la hegemonía de Francia en Europa. Por otra parte, tan solo unos treinta años antes los otomanos habían sitiado Viena por última vez (1683), cosechado un desastroso resultado. Este fracaso, confirmado en el Tratado de Karlowitz (1699), supuso el final de su expansión por el este de Europa. A partir de entonces el país entró en un período de decadencia política que normalmente se conoce con el nombre de Lâle Devri (Era de los tulipanes).

Mientras lord Montagu y su familia partían hacia su destino a principios de agosto de 1716, los otomanos fueron derrotados de nuevo por los austriacos en

\footnotetext{
${ }^{1}$ Todas las citas directas y referencias de las Cartas provienen de la traducción de Celia Filipetto. El número romano indica la carta y el árabe la página del libro.
} 
la batalla de Petrovaradín. Este enfrentamiento, además de causar la muerte del Gran Visir Silahdar Damat Ali Bajá, significó la pérdida de una parte importante de Serbia y colocó al sultán en una posición difícil. No deja de resultar interesante que fuera precisamente por esa ciudad por la cual seis meses después el embajador Montagu y su familia entraron en el Imperio Otomano (XXIV, 81).

Lady Montagu decidió acompañar a su marido a Oriente y llevar también a su hijo, aún muy pequeño, lo cual no era la norma general en esos tiempos. En esta decisión debió influir tanto la lealtad a su esposo o la idea de que podía ayudarle en su misión como el deseo por no desaprovechar una oportunidad tan atractiva. Como ella misma confiesa en sus Cartas: «sigue gustándome viajar» (I, 24) y «Me gusta viajar en grado sumo» $(X X V, 86)$. El viaje de ida duró unos seis meses y transcurrió por Holanda, Alemania, Austria y Hungría. Sabemos que lady Mary se documentó con profusión antes de partir leyendo varios relatos de viajeros anteriores por el Imperio (Robert Withers, George Sandy, John Covel, Jean Dumont, Aaron Hill) y algunas obras orientales como Las mil y una noches (que A. Galland había comenzado a traducir al francés en 1715). Todas estas lecturas serían para ella una gran decepción al entrar en contacto con el verdadero Oriente: piensa que lo que ella ve es mucho más interesante y menos extraño que lo leído en los libros. A menudo criticará lo que otros viajeros contaron o los acusará directamente de decir falsedades para mantener contento a un público ávido de diversiones y exotismo (XXI, 73). Pero esto no solo ocurre con la información sobre el Imperio Otomano, también con datos de otros países por los que pasa, como Austria (XX, 69).

En su primera carta a la princesa de Gales comenta:

he realizado hasta ahora un viaje jamás emprendido por ningún cristiano desde los tiempos de los emperadores griegos y no lamentaré las fatigas padecidas si con ello tendré la oportunidad de distraer a su Alteza Real describiéndole lugares completamente desconocidos entre nosotros, pues los embajadores del Emperador y los pocos ingleses que han llegado tan lejos siempre lo han hecho navegando por el Danubio hasta Nicópolis. (XXVI, 87)

Este pasaje llamó en el pasado la atención de muchos investigadores y, a menudo, fue utilizado para demostrar que lady Mary no era fiel a la realidad, ya que los Montagu no eran los primeros viajeros occidentales en llegar a territorios otomanos. Algo similar le dirá al escritor Alexander Pope:

Me atrevería a decir que en esta carta espera usted al menos algo muy nuevo, después de haber pasado por un viaje que ningún cristiano ha emprendido en cien años. (XXXI, 108)

Pero es evidente que está refiriéndose a la forma en que accedieron al Imperio (por vía terrestre, durante el invierno y en plena guerra), algo de lo que se muestra especialmente orgullosa por el enorme riesgo que había implicado. Además, es una de las distintas formas que tiene de replicar a los viajeros anteriores que no supieron acercarse a la realidad del país que visitaban: «He 
entrado en un mundo nuevo y todo cuanto veo me parece un cambio de escena» (XXVII, 89).

La estancia terminó en junio de 1718, cuando lord Montagu fue súbitamente relevado de su cargo por presiones del embajador austriaco ante la Puerta (que lo percibía demasiado cercano a la causa otomana, sensación en la que debió influir la actitud pro-turca de su esposa). La vuelta a Inglaterra fue en barco pasando por los Dardanelos y las islas de Lesbos, Sicilia y Malta hasta llegar a Túnez (por aquel entonces bajo soberanía otomana) y de ahí a través de Francia. Algunos de los comentarios de lady Mary en esta travesía son sumamente reveladores de que su apego por los turcos se limitaba a determinadas clases y lugares del Imperio: las comunidades griegas que visita le parecen pobres y sin ninguna relación con las ruinas clásicas que contempla; y los habitantes de Túnez tan solo le merecen comentarios racistas (L, 193-204).

Las Cartas se publicaron en 1763, un año después de la muerte de Lady Mary, gracias a que ella misma se había ocupado de entregar una copia al reverendo Benjamin Sowden en Rotterdam, puesto que las cartas originales fueron quemadas por su hija lady Bute en el mismo momento del fallecimiento de su madre. En 1794 correrían el mismo trágico destino muchos de sus diarios (Murphy 1988: 35-37). Finalmente, su nieto lord Wharncliffe realizó en 1835 la primera edición completa de todos sus escritos (Warnock Fernea 1981: 337). El inmediato éxito de las Cartas llevó a una constante reimpresión y a su rápida traducción a otras lenguas europeas. De ahí que su influencia en el mundo ilustrado de la época fuera enorme. Uno de los primeros intelectuales en dar su opinión fue Voltaire (Murphy 1988: 37), quien ya le había aplaudido en vida su campaña en pro de la inoculación de la viruela (vid. infra) ${ }^{2}$ y elogió ahora su talento literario y sus dotes para la observación (Kaplan 2008: 58). Con posterioridad, muchos otros escritores y artistas se inspiraron en ellas a la hora de realizar sus obras, como, por ejemplo, el pintor Jean-Auguste-Dominique Ingres (Warnock Feernea 1981: 330).

Las Cartas ayudaron a extender una imagen positiva de los otomanos que contrastaba notablemente con la existente y favorecieron la eclosión en las distintas cortes europeas de una moda «a la turca» en decoración, ropa, pintura, música, comida, etc., conocida con el término francés de turquerie. Este estilo había comenzado en Occidente a finales del siglo XVI pero en el XVIII revivió con fuerza precisamente por el aumento de los viajeros europeos al Imperio. ${ }^{3}$ A partir

\footnotetext{
${ }^{2}$ Lettres Philosophiques (1733, cap. XI).

${ }^{3}$ El escritor turco Ahmet Hamdi Tanpinar opinaba (en su obra 19. Asir Türk Edebiyat Tarihi, İstanbul, Çağlayan Yayınevi, 1976, p. 44) que algo similar ocurrió en sentido contrario, ya que fue precisamente en la época del sultán Ahmet III cuando las clases altas del Imperio Otomano comenzaron a adoptar algunos elementos europeos en lo relativo a la ropa, la decoración y el gusto en general, muy especialmente a partir de la subida al poder del Gran Visir Damat İbrahim Bajá (1718-1730).
} 
de ahí abundan los retratos de muchos nobles vestidos «a la turca», algo en lo que la propia lady Montagu no sería una excepción. ${ }^{4}$

En las Cartas introdujo datos muy diversos sobre temas variados, aunque no con ánimo de vanagloriarse ante sus interlocutores sino con el objetivo de informarles de manera exacta (XXIII, 80) y dar un marco comprensible a su relato. Lady Montagu es siempre consciente de que lo que ella cuenta va a romper con los estereotipos, de que no encaja en la imagen que se tiene de los otomanos y que, precisamente por eso, va a resultar difícil de creer para la gran mayoría (XXVII, 92-93; XXXII, 117; XXXIII, 120 Y 123-4; XXXIV, 126 Y 130; XXXVIII, 146-7; XLI, 161; XLVIII, 182; XLIX, 190). Sería más fácil, dice, incluir unas cuantas mentiras sorprendentes (XXX,107-8; XLI, 163). Pero durante todo el relato insiste en que desea contar lo que ve, aunque contradiga todo lo dicho hasta entonces. De hecho, sabemos que su hija, que a la muerte de lady Mary intentó por todos los medios que las Cartas no fueran publicadas, pretendió desacreditarlas a posteriori extendiendo la falacia de que no eran auténticas, de ahí que contaran cosas distintas a lo habitual (Murphy 1988: 36-37).

\section{LAS CARTAS DESDE ESTAMBUL EN TURQUÍA}

Durante varios siglos no hubo ningún tipo de interés ni reacción turca a las Cartas de lady Mary, a pesar del enorme eco que despertaron en Europa. Esto ya de por sí parece un dato digno de ser reseñado y es una muestra del poco interés que existía, y que en algunos aspectos aún pervive, por «el Otro» en Turquía. La primera traducción al turco apareció en 1912 con el título de Şark Mektupları (Cartas de Oriente) y fue hecha por el historiador Ahmet Refik, el cual añadió algunas notas explicativas. La edición probablemente partió de una versión francesa, pero en ella solo aparecían las cartas escritas en territorio otomano, algo que ha marcado la tónica general en todas las traducciones posteriores. Esta misma traducción, renovada lingüísticamente y en caracteres latinos, fue reimpresa en 1933.

Pero posiblemente la que ha tenido más difusión e influencia fue la preparada por Aysel Kurutluoğlu para la editorial del periódico Tercüman en 1970, a partir de una cuidada edición inglesa, ${ }^{5}$ que se tituló Türkiye Mektupları. 1717-1718. Este libro se incluyó dentro de un programa de traducciones de

\footnotetext{
${ }^{4}$ Lady Montagu fue pintada en varias ocasiones con un atuendo «a la turca». En el cuadro pintado por Jonathan Richardson el Joven (1725) se la representa con un niño turco detrás. En otro de Jean Baptiste van Mour (1717) la vemos acompañada de su hijo y dos sirvientes turcos. También se conserva en la National Gallery un grabado que perteneció a la colección privada del conde Harrington, el mismo con el que se confeccionó la cubierta de la traducción al español publicada por La Línea del Horizonte. Pero tal vez el retrato más interesante sea el pintado por Jean-Étienne Liotard (h. 1756).

${ }^{5}$ The Complete Letters of Lady Mary Wortley Montagu, vol. 1: 1708-1720, Robert Halsband (ed.), Oxford University Press, 1965.
} 
clásicos organizado por el periódico a partir de 1963 que fue adoptado luego por el Ministerio de Educación turco. ${ }^{6}$ No obstante, debemos tener en cuenta que iba destinado a un público principalmente juvenil. A partir de finales del siglo XX han aparecido numerosas traducciones y ediciones, pero siempre de las cartas en Turquía y, a menudo, no desde la lengua original. El hecho de no incluir el resto de las cartas indica el poco interés editorial y académico por lo que lady Montagu dijo sobre otros lugares. Desgraciadamente al hacer eso no solo suprimen el marco general en que fueron escritas, sino que interfieren notablemente en su significado, pues muchos de los comentarios de lady Mary con respecto a los otomanos no se entienden muy bien sin contrastarse con lo dicho anteriormente de otros pueblos o países.

La tónica general con la que los académicos turcos reciben las Cartas es muy positiva: se alaba la imagen objetiva que da del Imperio, de sus habitantes, de sus costumbres y de su religión. Elogian su mirada nueva y sus intentos por entender vida, lengua y costumbres. Y, sobre todo, se enfatiza el hecho de que lady Mary pretenda siempre ser fiel a la verdad, en lugar de caer en la visión orientalista preexistente que se limitaba a repetir sin más libros anteriores y tendía a acrecentar el sentimiento de superioridad de la civilización europea. ¿Opinarían lo mismo si esa visión hubiera servido para criticar a los turcos? Posiblemente no. No obstante, eso no significa que estén de acuerdo en todo lo que dice. Pero sí se muestran comprensivos con la escritora en caso de que cometa errores o hable de cosas que, a su parecer, no entendió muy bien. En realidad, más que los comentarios sobre las Cartas, es mucho más interesante observar qué temas no se mencionan o cómo la mayoría de las veces se limitan a citarlas sin incluir después ningún tipo de interpretación.

\section{TEMAS TRATADOS POR LOS ACADÉMICOS TURCOS}

\subsection{El desconocimiento del mundo otomano en Europa}

Hay una serie de cuestiones que casi todos los turcos coinciden en resaltar. En primer lugar, el gran desconocimiento que había en la Europa de la época de la realidad otomana (Baktır 2016: 25-6, Demir 2014, Çolak 2010: 387, Gündüz 2019: 133, Kaçmaz y Çoban Döşkaya 2017: 24, Oğuzhan Börekci 2013: 190-1, Umunç

\footnotetext{
${ }^{6}$ El programa se conoció con el nombre de Tercüman 1000 Temel Eser (1000 Obras Básicas del Tercüman) y fue una iniciativa personal del propietario del periódico, Kemal Ilıcak. En 1967 el Ministerio de Educación se apropió de la idea y creó un proyecto similar, Bin Temel Eser (1000 Obras Básicas), que no estuvo falto de polémica por la forma en que eran seleccionadas las obras. Finalmente, el Ministerio publicó solo sesenta y seis volúmenes entre 1969 y 1972. Pero el periódico prosiguió sacando algunos libros más cambiando el nombre general del proyecto por el de Tercüman 1001 Temel Eser. Ambos proyectos quedaron paralizados con el golpe de estado producido el 12 de marzo de 1971, aunque la idea ha sido retomada varias veces con posterioridad.
} 
2013: 303), de ahí que lady Mary critique a menudo los escritos de los viajeros precedentes e intente hacer un relato realista. En este sentido, algunos perciben sus Cartas como una especie de obra etnográfica (Baktır 2016) ya que describe a personas de otro mundo costumbres, edificios, ropa, fiestas, animales, etc., como si fuera una investigadora que analiza una cultura ajena. Por otra parte, algunos académicos (Demir 2014, Kaplan 2008: 57) señalan que todo lo reseñado por lady Montagu no solo es de gran interés para los europeos (tanto los del siglo XVIII como los actuales) sino que se ha convertido en una valiosa fuente de información sobre la vida cotidiana de las clases altas otomanas de esa época, un período para el que se carece casi por completo de documentos en turco sobre esos temas. Y lo aprecian todavía mucho más al venir de manos de una mujer. Este comentario resulta igualmente válido para otros aspectos, como la influencia militar en la sociedad o la valoración de la arquitectura local, algo de lo que las fuentes otomanas no suelen hablar.

Algunos (Oğuzhan Börekci 2013: 191), aunque reconocen el valor de los datos que aporta, lo interpretan como un intento occidental más por dominar al «Otro», aunque de una manera más sutil. De ahí que insistan en que a menudo son informaciones «de segunda mano» que no están contrastadas, y la tachen de ser una mera «aficionada», sin pararse a pensar que lady Montagu no era una investigadora moderna. También parecen olvidar que las personas que informaban a lady Mary eran turcas y que, puesto que ella transmitía lo que le contaban, la «culpa» de las posibles inexactitudes estaría en los propios turcos.

Por supuesto existe la posibilidad de que en algunos aspectos lady Montagu no entendiera bien a sus interlocutores locales o que incluso malinterpretara a propósito lo que le contaban. Pero desde luego están muy equivocados al pensar que en la Europa de principios del XVIII había un desconocimiento total de los otomanos. Ciertamente muchos de los datos que llegaban eran sesgados o erróneos; pero había información, y mucha, que se transmitía gracias a embajadas, espías, viajeros, comerciantes, etc. De hecho, el siglo XVIII fue un momento de eclosión del interés por todo lo que pasaba en el Imperio Otomano que coincidió con el inicio de su decadencia político-militar y el comienzo de una época en que los equilibrios de poder estaban cambiando. Por el contrario, no podemos decir que los otomanos tuvieran la misma disposición por entender a los occidentales.

Otra crítica sostiene que lady Montagu ofrece informaciones excesivamente básicas (Kaplan 2008: 57). En este caso la cuestión radica en qué entendemos por «básico». Desde luego, es probable que muchos de los temas que lady Mary trata sean ampliamente conocidos por cualquier lector turco bien educado (aunque no está tan claro que sea siempre así). Pero si lady Mary quería ser bien entendida por su público necesitaba explicarlo todo de forma fácil y sencilla aportando muchas aclaraciones y partiendo de lo más elemental. Porque ese público (damas de la corte inglesa, en su gran mayoría) carecía de casi cualquier conocimiento de Oriente. 


\subsection{Las mujeres y su mundo}

Los comentarios de lady Montagu sobre las mujeres otomanas y su forma de vida son, quizás, el aspecto que más se ha analizado. Su inmenso interés por conocer las costumbres del país la llevó a introducirse en ambientes hasta entonces nada frecuentados por otras mujeres europeas. Accedió a las mansiones de diferentes damas de la clase alta otomana y logró mantener con algunas una relación fluida que posibilitó el intercambio de información. Esta situación le suministró un mejor conocimiento de su manera de vivir. Pero también, algo que tiende a olvidarse, ayudó a las otomanas a entender a las europeas. No obstante, no podemos dejar de lado que casi todos sus comentarios se refieren a señoras de alto rango, cuya vida transcurría de forma distinta a la de las mujeres de clase media y baja, clases con las que lady Mary no mantuvo ningún contacto.

Algunos turcos que analizan este tema utilizan los comentarios de lady Montagu acerca de la belleza de las mujeres, su exquisita educación, la forma atenta en que tratan a la invitada inglesa, etc., para demostrar la superioridad de la cultura otomana sobre la europea (Oğuzhan Börekci 2013: 192-4), sin ser conscientes de que era lógico que las mujeres turcas de clase alta pretendieran epatar a la extranjera enseñándole «lo mejor de la casa» y olvidando igualmente que lady Montagu está haciendo los cumplidos habituales en ese tipo de situaciones. Otros nos remiten a las turquerie (vid supra). Pero esta moda no implicaba una aceptación real del «Otro» sino, más bien, una apropiación de su cultura como algo exótico y novedoso (Gündüz 2019: 125). No obstante, las influencias fueron a veces muy positivas $\mathrm{y}$, como ya hemos dicho antes, también existió por las mismas fechas la corriente espejo entre los otomanos de manera que poco a poco se fue imponiendo en las clases altas del Imperio un estilo «a la europea».

Uno de sus primeros contactos con el mundo femenino fueron los baños turcos, el hamam, en la ciudad de Edirne (XXVII, 89-93). Este no fue el único hamam que lady Mary visitó, pero tal vez sí el que le produjo mayor impresión al tratarse del primero. Lady Montagu queda deslumbrada por la arquitectura y el funcionamiento, así como por el ambiente que contempla: lejos de ser un mundo de perversiones sexuales y voluptuosidad decadente, el hamam se transforma a sus ojos en un lugar de aseo, descanso, esparcimiento, cotilleo y reunión. Ella lo compara con el papel que los cafés desempeñan para los hombres (XXVII, 92) y todos los escritores turcos opinan que es una comparación muy acertada (Baktır 2016: 19, Demir 2014, Baysal 2009: 600). También le parece bastante igualitario, ya que las mujeres que lo frecuentan pertenecen a diferentes clases, muchas de ellas son incluso esclavas, pero, al ir todas desnudas, es imposible distinguir su origen social.

Çolak explica que algunos académicos turcos han negado que las mujeres otomanas acostumbraran a estar totalmente desnudas en los hamam, de ahí que 
opinen que lady Mary sigue aquí un imaginario propio de la visión orientalista. ${ }^{7}$ Sin embargo, se equivocan (2010: 388) y son ellos los que están proyectando hacia el siglo XVIII una situación que todavía les resulta inmoral en el XXI. Lady Montagu cuenta también que las mujeres suelen ir al hamam una vez a la semana y que se demoran allí cuatro o cinco horas. Admira su belleza y cortesía para con la extranjera y, al final, se ve obligada a enseñarles su corsé para apaciguar el interés por ese «instrumento» que las turcas piensan su marido la obliga a llevar y que solo él puede abrir (XXVII, 92). No será la única vez en que se muestren atraídas por la forma de vestir y las costumbres de la europea, como podemos apreciar también en XLI, 164. Pero este interés por la occidental no suele ser reseñado por los académicos turcos.

Por supuesto, la aparente igualdad del baño no era tal: las esclavas estaban ahí acompañando a sus amas y, aunque todas se despojaban de ropas y joyas, las clases se mantenían en los diferentes lugares que usaban para lavarse o reunirse. Además, lady Montagu olvida o desconoce que las mujeres de las minorías no podían ir al hamam al mismo tiempo que las turcas. Por otro lado, el comentario sobre su corsé es muy reseñable: las otomanas parecen incapaces de comprender que alguien se ponga por gusto o por mera moda semejante armadura y por eso adaptan el concepto a su forma de entender el matrimonio. Desgraciadamente, ningún académico habla de eso, como si mostrar curiosidad e interés por «el Otro» solo tuviera que funcionar en una dirección (de los occidentales hacia los orientales). Sin embargo, algunos sí indican que lady Montagu no se da cuenta de la importancia que los baños tenían como uno de los principales centros para concertar matrimonios: allí podían verse las futuras novias y, sobre todo, podía apreciarse si tenían algún defecto físico que, más tarde, pudiera servir de excusa para que los novios devolvieran a la muchacha provocando su deshonra y la de su familia (Baktır 2016: 19-20). Un dato que, lógicamente, ella no podía saber si nadie se lo decía.

Con posterioridad, Lady Montagu fue invitada a realizar una serie de visitas a las damas de mayor alcurnia del Imperio (exceptuando el harén del sultán), dado que en esos momentos la corte estaba asentada en Edirne. Conoce a la esposa del Gran Visir (XXXIV, 125-127), a la viuda del anterior, recientemente muerto en la guerra (XXIX), y a la mujer del segundo funcionario de la corte (XXXIV, 127-131). Más tarde, entrará en contacto con otras damas principales, ya en Estambul, como la favorita del sultán anterior, la sultana Hafise (XLI, 157-162). La opinión general que le merecen todas ellas es abrumadoramente positiva: dejando de lado sus diferentes caracteres, el lujo de las mansiones, su aspecto elegante y delicado pero al mismo tiempo único, la buena educación tanto de las damas como de las mujeres que las acompañan, su agradable compañía, su discreción, etc., cosechan todo tipo de alabanzas. Lady Mary ofrece amplias

\footnotetext{
7 Al respecto se puede consultar Sancar, A. (2009), Osmanlı Kadını Efsane ve Gerçek, İstanbul, Kaynak Yayınları, p. 12.
} 
descripciones de todo lo que ve, sabiendo que sus amistades inglesas sabrán apreciarlas.

En sus visitas es testigo de la gran cantidad de mujeres que viven en los harenes. Estas mujeres se llamaban de manera general cariye $e^{8}$ desde el principio lady Montagu observa que son en su mayoría sirvientas de diferentes tipos. Muchas eran niñas de corta edad que eran adiestradas en diferentes artes por las mayores (música, baile, bordado, canto, poesía, caligrafía, etc.) (XLI, 162-3). Su educación era esmerada y el precio que se pagaba por ellas después, en caso de que fueran vendidas, muy elevado. Pero lo más importante es que, a pesar de los relatos de muchos occidentales, la mayoría de las mujeres de los harenes no eran concubinas del dueño de la casa. De hecho, solo un número muy reducido podían considerarse verdaderamente como tales, el resto eran ayudantes y sirvientas. Pero casi todas ellas eran esclavas.

Lady Mary solo ve las más vistosas e instruidas, pues las damas turcas que la agasajan tienen especial interés en que ella se lleve una impresión favorable. De ahí que se muestre impresionada por la delicadeza con la que sus dueñas las tratan (XXXIV, 127-8 y 130; XLI, 162) y opine que no son oprimidas ni violentadas y que viven alegres. También comenta que la historia del pañuelo lanzado por el sultán a la concubina con la que desea pasar la noche es totalmente falsa: es el eunuco principal del serrallo quien se ocupa de comunicar la noticia a la elegida. La primera de las elegidas, no la madre de sus hijos, se convierte entonces en la dama de mayor rango (XLI, 161) (Oğuzhan Börekci 2013: 194). Lo que no le explican, sin embargo, es que la señora principal del harén del sultán era habitualmente la madre del monarca.

Meses después insiste en ofrecernos una visión de los esclavos diferente a la imagen habitual: su situación, según ella, es similar a la de los sirvientes en Europa y nunca son maltratados ni utilizados con propósitos perversos (XLVI, 178). Opina que un buen número de muchachas inglesas sin dote se ven en peor situación que las cariye, pues deben casarse, aunque no lo deseen para poder sobrevivir. Por supuesto, estas ideas deberían ser muy matizadas: el trato a las esclavas de categoría no sería el mismo que el recibido por las «normales», mucho menos si estas vivían en casas menos señoriales. Por no hablar de otro tipo de esclavos que desempeñaban trabajos más pesados.

Lady Montagu deja muy claro que los harenes no son lugares creados para satisfacer la concupiscencia masculina, sino zonas privadas que protegen a las mujeres, donde esposas y sirvientas viven preocupadas por la crianza de los hijos desarrollando una mutua solidaridad y donde abundan las visitas y las

\footnotetext{
8 Es imposible dar una traducción neutra a esta palabra (que proviene del árabe جارية). En español usamos el término «odalisca» que procede del francés odalisque, al que llegó desde el turco odalik (referido a oda [cámara, habitación]) por lo que su sentido original era el de «camarera»). Pero la palabra odalisca conlleva un elemento orientalista considerable. Traducirla por «concubina» sería un error ya que, como indico en el texto, no siempre lo eran. Tal vez lo más adecuado fuera decir simplemente «esclava del harén».
} 
actividades culturales. Esta imagen idílica, a pesar de lo mucho que gusta a los turcos modernos, era posiblemente tan irreal como la del foco de desenfreno sexual difundida con anterioridad. Sabemos que a principios del siglo XVIII ya no era frecuente entre los hombres de las clases altas otomanas tener más de una esposa, entre otras cosas porque la primera solía ser una dama de buena familia o una antigua esclava del serrallo imperial con la que el sultán «premiaba» a sus colaboradores más cercanos y a la que estos no podían despreciar. Pero eso no quiere decir que la poligamia hubiera dejado de existir, ni que el dueño de la casa no pudiera tener varias concubinas si así lo deseaba, ni que la mayoría de las mujeres que vivían en los harenes fueran libres. Cuando lady Mary explica que los maridos «necesitan» el permiso de sus esposas para tener relaciones con otra mujer del harén $(X X X, 107)$ creo que está limitándose a repetir lo que esas esposas le cuentan, algo más bien deseado que real. Solo las más influyentes o poderosas debían tener la posibilidad de impedirlo. Por otro lado, el hecho de que algunos maridos tuvieran a sus amantes instaladas en casas aparte le resulta muy normal (XXX,107), posiblemente porque en el Londres de la época también lo era. Pero no debía ser la tónica general.

Hay un episodio muy interesante en la Carta XXXVIII cuando lady Mary responde a una de sus conocidas de Inglaterra que, sintiéndolo mucho, no va a poder comprarle la esclava griega que le había encargado (p. 146). Le explica que las griegas no son esclavas sino súbditas del sultán, rompiendo así con otro de los tópicos occidentales, este difundido posiblemente por los mismos griegos. $\mathrm{Y}$ añade que las buenas esclavas, como ya hemos visto más arriba, son una «mercancía» carísima y al alcance de pocos bolsillos.

Lady Montagu trata algunos otros temas relacionados con las mujeres como el hecho de que las casadas sin hijos sean un oprobio para la familia y para ellas mismas porque la fertilidad es uno de los valores femeninos más importantes. Por eso los embarazos se repiten a intervalos muy cortos y todas las familias tienen numerosos hijos, sabiendo que posiblemente muchos de ellos no llegarán a la edad adulta (XXXIX, 150). Los embarazos tampoco se esconden con ropas especiales y las mujeres no permanecen ocultas sin recibir visitas después del parto (XLI, 157). Aunque, claro está, dichas visitas serían solo de otras mujeres y en estancias cerradas. Tampoco permanecen divorciadas o viudas mucho tiempo, a pesar de que económicamente son independientes pues conservan su dote y posesiones tras el divorcio o la muerte del marido, por lo que no necesitarían casarse para sobrevivir (XXX, 107; XL, 153). A la inglesa eso le parece el colmo de la autonomía por lo que no comprende esa necesidad (İnan 2017: 7). ${ }^{9}$ Primero le

\footnotetext{
${ }_{9}$ Si tenemos en cuenta los problemas que la propia lady Montagu vivió cuando su padre y su futuro marido no se pusieron de acuerdo en los intercambios económicos necesarios para su matrimonio y si pensamos que en la Europa de aquellos años cualquier mujer dependía totalmente de su tutor masculino (padre, hermano, marido) para manejar sus posesiones y su dinero, resulta lógico que no entienda que las otomanas se empeñen en casarse cuando tienen ese aspecto de la vida asegurado. Lady Montagu también pasó ciertos apuros cuando comenzó a
} 
explicarán que se debe a motivos religiosos, pero más tarde comentará que seguramente sea porque las mujeres que viven solas no tienen fama de honorables (XLVIII, 186).

Posiblemente lo que más ha llamado la atención de sus Cartas es la afirmación de que las mujeres turcas son mucho más libres que las occidentales, aunque en realidad este comentario suele sacarse de contexto. Lady Mary lo dice por primera vez cuando habla de la ropa que las otomanas se ponían para salir a la calle: un ferâce o especie de capa larga que cubría sus vestidos completamente y el peçe o velo tupido en la cara. De esa forma, cualquier mujer era igual a otra y resultaba imposible distinguirlas, por lo que eran libres de actuar a su antojo. $Y$, como ella misma dice, eso les proporcionaba una invisibilidad positiva pues les permitía tener amantes con facilidad (XXX,106-7). Si a esto unimos el hecho de que contaban con dinero propio es lógico que comente: «considero a las mujeres turcas como las únicas personas libres del imperio» (p. 107). Pero ella está hablando solo de las damas de alta alcurnia comparándolas con las europeas, que tenían mucho más difícil no ser reconocidas en la calle o en otros lugares y que tampoco podían manejar su propia fortuna. De ahí a creer en una verdadera libertad femenina va un largo trecho. Por otro lado, lady Mary no pretende en absoluto dar a entender que las mujeres turcas son más inmorales que las occidentales; más bien opina que en ese aspecto no hay diferencia entre ambas: «En cuanto a su moralidad o buena conducta puedo decir, como Arlequino, que es tal como es entre vosotros» (p. 106).

Más adelante lady Montagu insiste en el tema de la libertad femenina:

las damas turcas que son, quizás, más libres que ninguna otra dama del universo, y las únicas mujeres del mundo que llevan una vida de ininterrumpido placer, libre de cuidados, y dedican todo su tiempo a hacer visitas, a bañarse o a la agradable diversión de gastar dinero e inventar nuevas modas. Por loco sería tenido el marido que exigiese cualquier clase de economía a su esposa, cuyos gastos no tienen más limitación que las impuestas por la propia fantasía. El trabajo de él es ganar dinero y el de ella gastarlo, [...]. Viajan al extranjero cuando y adónde les place. Es cierto que no tienen más lugares públicos que los baños y allí solo pueden ser vistas por las de su mismo sexo. (XLVIII, 183)

Creo que este párrafo es un buen ejemplo de la «libertad» a la que lady Mary se refiere: queda claro que está hablando de las mujeres de clase superior, cuya vida está resuelta en todos los aspectos. Pero también es evidente que no son tan libres como las europeas y, desde luego, en absoluto libres para los estándares de nuestra época. Por otra parte, su alusión a «viajes al extranjero» parece totalmente exagerada sobre todo cuando al mismo tiempo nos está diciendo que no tienen

vivir separada de su esposo hacia 1739 (Murphy 1988: 16-20 y 31-5). Lo que tal vez ella no sabía es que las turcas necesitaban casarse al menos una vez para poder disponer libremente de su dote y que, a pesar de que en teoría esta no podía ser tocada por los maridos, a menudo eso no era tan fácil de impedir. 
acceso a la vida pública y que ni siquiera pueden asomarse a ella si no es detrás del velo y el ferâce.

Lady Mary es también consciente de que existe otra realidad, en la que entran los malos tratos hacia las mujeres, algo que queda en evidencia cuando relata la aparición del cuerpo de una mujer asesinada en su barrio y alude a los «crímenes de honor»: el culpable no es perseguido ni juzgado por el Estado y explica que son los parientes los que suelen vengar a la muerta (XLVIII, 184-5). Pero, a continuación, tal vez para rebajar el mal gusto de esa historia, introduce un episodio novelesco que ayuda a suavizar la tensión: las aventuras de una española napolitana que, tras ser capturada por los berberiscos, acabará casándose con su secuestrador (XLVIII, 185-6), como si se tratara de una auténtica novela bizantina. Ambos sucesos son poco comentados y los que lo hacen se limitan a reseñar el primero, prefiriendo demorarse más en el segundo, una historia mucho más amable y que sirve, además, para criticar la mala fama de bárbaros que los turcos de la época tenían en Occidente (Kaplan 2008: 61), como si un solo ejemplo de «final feliz» fuera suficiente para hacer olvidar el grave problema de los corsarios.

Los académicos turcos modernos prefieren repetir las alabanzas de lady Montagu a las mujeres, a su educación y elegancia, y admiran con ella la opulencia de sus mesas y la magnificencia de ropas y joyas (XXXIV; XLI). En ocasiones parece que estuviéramos presenciando un concurso, de tanto como insisten en que la visión de lady Mary pone a las otomanas a un nivel no solo equiparable sino a menudo incluso superior al de las mujeres occidentales (Kaplan 2008: 192). Algunos llegan a decir que es probable que lady Montagu esperara encontrarse a damas poco agraciadas, ignorantes o mal educadas, de ahí su sorpresa (Çolak 2010: 395). Parecen olvidar que valorar los méritos de «el Otro» formaba parte de la actitud abierta y positiva con la que lady Mary intentaba acercarse a ese mundo desconocido.

Subrayan mucho dos tópicos que persisten en la actualidad: la generosa hospitalidad y la inmensa variedad culinaria (Kaçmaz y Çoban Döşkaya 2017: 28 y 31-2). La primera era casi obligada si las damas otomanas querían causar buena impresión y con respecto a la segunda habría que puntualizar que lady Mary no se refiere en realidad a la diversidad de la comida otomana sino a la presentación de las mesas con gran cantidad de pequeños platos y a la novedad que supone para ella ese estilo de comidas. De hecho, tras una temporada en Belgrado disfrutando de la cocina local, confiesa que preferiría tener un cocinero inglés que le guisara todo a su manera (XXXIV, 126-7).

Sin embargo, el tema de las esclavas es a menudo «olvidado». Los que lo tratan se limitan a reseñar que tanto la esclavitud de las mujeres como el misterio del harén se habían convertido hacía tiempo en materias comunes en la literatura de viajes occidental. Otros elogian el hecho de que lady Mary enfoque el tema de los esclavos desde un punto de vista más positivo que el resto de los viajeros, al explicar que no recibían malos tratos ni eran vejados sistemáticamente por sus 
amos (Demir 2014). No obstante, no suele haber explicaciones acerca de la vida real de las esclavas en los harenes, tal vez porque la documentación de la época es escasa y no acostumbra a tratar ese tipo de cuestiones. O porque la mayoría de los turcos desconocen el asunto con profundidad. Pero es que tampoco aventuran una opinión al respecto y prefieren pasar de puntillas por el hecho de la existencia de la esclavitud en el siglo XVIII. Por supuesto que el tópico de las odaliscas voluptuosas o maltratadas existía, pero desembarazarse del tópico no implica que la esclavitud fuera generalmente un camino de rosas o que los harenes tuvieran las puertas abiertas. Las esclavas jóvenes y bien educadas eran un bien preciado para sus amos, entre otras cosas por el dinero que habían invertido en ellas. No obstante, seguían siendo consideradas una mercancía y es muy probable que existieran abusos. Lady Montagu solo fue testigo de la cara más amable del asunto y por ese motivo sus conclusiones fueron muy positivas. Tampoco es de extrañar que no se horrorizara, ya que por aquel entonces la esclavitud existía también en Inglaterra. ${ }^{10}$

Los comentarios más sorprendentes son los relativos a la supuesta libertad femenina de la que hablaba lady Montagu. Dan por hecho que esta existía, sin pararse a recapacitar si esas mujeres «libres» que salían a la calle totalmente tapadas y con el debido permiso de sus familiares varones y que podían entretenerse con amigas o incluso tal vez tener amantes no eran toda la población sino solo un segmento mínimo y selecto. Muchos académicos turcos se concentran en defender la moralidad de las otomanas, dejando de lado elementos más interesantes, como su independencia económica (con algunas excepciones, como İnan 2017: 6). Por un lado, todos explican que llevar una capa y un velo en los lugares públicos era algo propio de la época. ${ }^{11}$ Por otro, se critica que el mero hecho de vestir así sirviera como excusa para ningún tipo de propósitos inmorales.

La propia lady Montagu usó esa ropa en sus visitas a las mezquitas y en algunos de sus paseos por la península histórica de la capital, precisamente porque eso la convertía en una noble otomana más y la ayudaba a pasar desapercibida, algo que a ella le interesaba vivamente, dada la expectación que sus recorridos por la ciudad despertaban entre los hombres. Pero ella está hablando siempre de las damas nobles de alto origen. Y más que «libertad» (aunque use esa palabra específica) está refiriéndose a las «posibilidades» de esas mujeres, comparándolas con las de sus conocidas y las suyas propias.

\footnotetext{
${ }^{10}$ Hasta 1807 no se prohibió la trata y la esclavitud no fue derogada hasta 1833 en el territorio de la metrópoli y un año más tarde en las colonias británicas.

${ }^{11}$ Algunos, incluso, dicen que era una costumbre «obligada» por el Islam, un comentario que resulta más propio del siglo XXI que del XVIII, y que ya de por sí es inconsistente, porque una gran cantidad de la población en Estambul y en el resto del Imperio no era musulmana y, sin embargo, también sus mujeres acostumbraban a llevar velo en las ciudades, como la propia lady Mary explica (XLVI, 174).
} 


\subsection{Los hombres}

Por lo que respecta a su punto de vista sobre los hombres del Imperio, lady Montagu se halló aquí en desventaja ya que solo tenía acceso a los círculos diplomáticos y extranjeros. Su primer y casi único contacto con un turco de clase alta se produce en Belgrado, cuando el matrimonio Montagu se hospeda durante su estancia en esa ciudad en la mansión de uno de los notables, Ahmet Efendi. La impresión que este hombre causa a la inglesa es extremadamente positiva: le describe como un caballero de esmerada educación, que cuenta con una buena biblioteca con todo tipo de libros y cuya conversación es interesante y refinada. Lady Montagu comenta con él lo que ha leído sobre el país y sus costumbres y son posiblemente las opiniones de Ahmet Bey las que por primera vez la llevarán a dudar de la exactitud de los escritos de los viajeros occidentales (XXIV, 84-5). También habla con él del confinamiento de las mujeres en los harenes y Ahmet Bey la convence de que no es algo tan perverso o negativo como se ve en Occidente. Incluso la idea de que las otomanas tienen grandes facilidades para engañar a sus maridos parece haber partido en origen del propio Ahmet Bey (p. 85) (Çolak 2010: 392). Le habla de poesía y en sus veladas actúa como un bon vivant que bebe vino al mismo tiempo que le da una explicación muy acomodaticia de los preceptos religiosos musulmanes: los nobles son deístas, pero ocultan sus ideas al pueblo, al que controlan mediante los predicadores (XXIV, 84 Y XXVIII, 95).

Por lo demás, el resto de sus impresiones son un tanto generales. El obligado contacto con las minorías y los comerciantes le hace llegar a la conclusión de que los turcos son demasiado orgullosos para dedicarse a los negocios (de ahí que los comerciantes más importantes, incluso la mayoría de los tenderos, sean principalmente judíos y armenios) (XXVIII, 93; XXXIV, 133). Tampoco se rebajan a hablar con los extranjeros, a no ser que estén seguros de que son personas importantes en sus propios países (XXXVIII, 147). Ninguno de estos aspectos es comentado por los académicos turcos.

\subsection{La política y la guerra}

Lady Montagu se refiere continuamente a los habitantes musulmanes del Imperio como «los turcos» porque así era como se decía en la Europa de la época, aunque es consciente de que dentro del país viven comunidades de origen diferente y a menudo habla de ellas. Los investigadores turcos modernos explican que es un término inexacto (por ejemplo, Gündüz 2019: 134), algo que parece innecesario, ya que se dirigen a un público turco culto que debería saberlo. Por el contrario, no parece llamarles la atención que hable continuamente de Adrianópolis o de Constantinopla o que, en general, use el nombre clásico de todas las ciudades por las que pasa en lugar del turco. 
Cuando lady Montagu llegó al Imperio Otomano, el sultán reinante era Ahmet III (1703-1730), el cual había accedido al trono tras una revuelta jenízara que derrocó a su antecesor. Este sultán decidió pronto establecer relaciones con Inglaterra en la idea de que ambos países podían colaborar para oponerse al expansionismo ruso. Pero su reinado estuvo plagado de conflictos que, en general, marcaron el inicio de la decadencia otomana y, finalmente, también él sería depuesto por los jenízaros. Pocos europeos de la época (y casi ningún otomano) eran todavía conscientes de ese declive; sin embargo, lady Montagu habla en sus cartas de los abusos de poder de los jenízaros y explica cómo ese antiguo cuerpo del ejército se ha convertido en un elemento desestabilizador para el gobierno del país. Porque tanto el sultán como sus gobernadores y toda la población en general están subordinados a sus intereses y exigencias (XXIV, 83; XXVI, 87).

No obstante, lady Mary explica que los verdaderos promotores de las revueltas son los notables provinciales, a los que ella llama de forma general «efendi» (XXXVIII, 94-5). El sultán no es, por consiguiente, el déspota despiadado del que hablan los occidentales: su capacidad de maniobra está muy limitada pues debe contar con el apoyo de los notables y los militares (XXIX, 99). También le llama la atención que el pueblo llano no manifieste sus opiniones de forma abierta como era ya común en Inglaterra, algo que atribuye al gran número de espías y a la opresiva jerarquía que todo lo controla (XXIX, 99-100). Su opinión personal es que el reinado pronto acabará y de manera sangrienta (XXXV, 138), como realmente ocurrió.

La mayoría de estos comentarios no son del gusto de los académicos turcos: aunque aplauden que ofrezca una imagen del sultán alejada del déspota sanguinario y bárbaro que era habitual en Occidente, tienden a pensar que lady Mary no fue capaz de comprender la labor crucial que los jenízaros desempeñaban en las campañas militares turcas (İnan 2017: 7), obviando que realmente eran una fuente continua de problemas internos. Algunos, incluso, critican que se sienta incómoda con la presencia continua de esos soldados en las calles y les parece mal que hable así de ellos para, yendo de una parte al todo, menospreciar al ejército otomano por levantisco y opresor. La opinión de lady Montagu sobre el papel desestabilizador de los notables y la falta de maniobra del sultán se ven igualmente como una manera de censurar a todo el sistema de gobierno turco (Oğuzhan Börekci 2013: 195-6). La falta de libertad de expresión y los abusos ni siquiera se comentan. Sin embargo, la visión de la inglesa resultó ser, a la larga, bastante acertada.

Lady Montagu tuvo la posibilidad de ver algún desfile y de visitar el campamento del sultán a las afueras de Edirne. Señaló la falta de entusiasmo dentro del ejército por iniciar una nueva campaña contra los austriacos y las quejas continuas del pueblo y los mercaderes por la guerra (XXXV, 134). De hecho, prácticamente desde su misma entrada en el país le llama la atención la actitud de los otomanos: la tropa que envían a la frontera para protegerlos en el 
camino duplica en número a la húngara que los ha acompañado hasta allí, aunque previamente se había pactado que ambas fueran exactamente iguales para no herir susceptibilidades. Para ella esto es un indicio de la propia inseguridad de los otomanos (XXIV, 82) y teme que la medida acabe provocando un conflicto. No obstante, algunos académicos opinan que pudo ser una maniobra para impresionar al enemigo (Çolak 2010: 390).

\subsection{Etnias y religiones}

En general, los turcos utilizan los comentarios de lady Montagu sobre la inmensa variedad de etnias (XL, 155) y lenguas (XLII, 169) para resaltar el cosmopolitismo del Estambul del siglo XVIII (Kaplan 2008: 196). En principio esto no debería extrañarnos ya que era la capital de un Imperio multinacional donde se englobaban gran cantidad de pueblos, culturas y religiones diferentes. En realidad, lady Mary no hace esos comentarios refiriéndose a la península histórica de la ciudad, donde generalmente vivían los musulmanes, sino a la zona de Pera, donde residían las minorías, los diplomáticos y los comerciantes extranjeros. Hasta que logra tener un nivel de turco suficiente como para manejarse con las damas otomanas a las que visita, lady Mary va acompañada por una intérprete griega. Eso nos indica que, al menos en la educación de las esas señoras, no estaban incluidos los idiomas extranjeros occidentales (de la misma manera, por otra parte, que las nobles europeas no aprendían persa sino francés). Sin embargo, los miembros de las minorías estaban acostumbrados a actuar de intermediarios entre países, lenguas y culturas. Incluso la parte de la administración de la Sublime Puerta que se ocupaba de las relaciones exteriores y los intercambios económicos estaba dominada también por las minorías. Esta realidad se evita por completo en todas las monografías.

Casi toda la información que hay en las Cartas sobre la religión musulmana se encuentra en las dirigidas al abad Conti, tal vez por tratarse él también de un hombre de religión. No obstante, a lo largo de todo el libro aparecen igualmente numerosas alusiones a los católicos («papistas») y a los ortodoxos, ante los cuales lady Montagu no se muestra ni comprensiva ni tolerante. Como primer acercamiento al Islam lady Mary dice: «es indudable que solo tenemos retratos imperfectos de las costumbres y la religión de estos pueblos» (XXVIII, 93). Posteriormente pasa a enumerar las distintas ramas del Islam y algunos de sus preceptos (XXVIII, 95-6), momento en el que vuelve a hacer aparición Ahmet Bey, el notable de Belgrado (vid. supra). Con todo, algunas de las cosas que él le explicó no dejan de resultar un tanto llamativas. Pretender, por ejemplo, que todo el que aprende el árabe puede entender fácilmente $E l$ Corán y aconsejar su lectura como algo muy agradable es algo que, en mi opinión, solo puede decir un musulmán que, o no lo ha leído mucho, o lo dice con intenciones propagandísticas. Ahmet Bey alega que la culpa de que a los europeos nos resulte extraño está en las traducciones sesgadas y la misma Lady Montagu explicará más adelante que la 
mayoría de las ideas equivocadas sobre El Corán provienen de los ortodoxos $(\mathrm{XL}, 153)$. Ahmet Bey afirma también que no existen ateos entre los otomanos, guardándose muy mucho de explicar que renegar del Islam estaba absolutamente prohibido. Pero él mismo se permite una serie de comentarios que dejan en evidencia que su fe es más bien relativa y de puertas para afuera (XXVIII, 96).

Lady Montagu habla asimismo de que los musulmanes tienen sus santones, igual que católicos y ortodoxos (XL, 153). Contempla una ceremonia de derviches giróvagos que describe con bastante exactitud, aunque la cansa, y dice que de ellos solo admira su austeridad y el aire contemplativo que desprenden (XXXV, 137 y XLVI, 179-180). Explica que para los musulmanes solo las mujeres casadas van al Paraíso (aunque este sea uno diferente al de los hombres), porque su misión principal en la sociedad es traer niños al mundo y cuidarlos, y esa es la razón de que las solteras y viudas deseen casarse rápidamente (XL, 153-4). También puntualiza que los turcos distinguen entre «placer» $\mathrm{y}$ «vicio» y por eso saben disfrutar de la vida. Son gentes refinadas que aprecian lo que tienen y se deleitan en la música, los jardines, las comidas, la poesía... mientras que los occidentales se ocupan de la política y la ciencia. Pero esa aparente sensualidad no significa que sean libertinos o incultos. Lady Montagu llega a decir que preferiría ser un notable rico a tener todo el conocimiento de Isaac Newton (XLIX, 192-3), una forma de expresar su atracción por ese mundo placentero del que ella parece pensar que Occidente está muy alejado.

El tema de la religión no es muy tratado entre los estudiosos turcos, que prefieren centrarse en otros asuntos. Valoran los intentos de lady Montagu por entender el Islam de una forma ilustrada (Kaçmaz y Çoban Döşkaya 2018: 32), mas a menudo se limitan a repetir sus palabras al respecto sin añadir ningún comentario. Sí aparecen, por el contrario, opiniones acerca de las visitas de lady Montagu a distintas mezquitas. La primera importante es la Selimiye en la ciudad de Edirne. ${ }^{12}$ Este templo es descrito con gran profusión en la Carta XXXV (136-7) y lady Montagu llega a decir que lo considera «el edificio más notable que he visto en mi vida» (p. 136) y que, a pesar de haber visitado otras mezquitas, iglesias y catedrales, piensa que esta «supera infinitamente a cualquiera» (p. 137). Estas palabras hacen que algunos turcos piensen que lady Montagu siente admiración por el Islam y sus manifestaciones religiosas, cuando en realidad ella simplemente está dejando constancia de su gusto artístico.

Más adelante, ya en Estambul, tendrá ocasión de conocer otras mezquitas imperiales, como la Süleymaniye (que le parece espléndida [XLVI, 176]). ${ }^{13}$ Pero

\footnotetext{
${ }^{12}$ Realizada por el arquitecto Sinan por encargo del sultán Selim II entre 1569-75 (aunque lady Montagu explica, por error que fue de Selim I), es considerada una de las obras cumbres del citado arquitecto y uno de los monumentos más importantes de Turquía.

${ }^{13}$ Construida también por Sinan a instancias del sultán Solimán el Magnífico entre 1550-7 era la más grande del país hasta 2019.
} 
tal vez la visita más curiosa sea la que realiza a Santa Sofía (XLVI, 175-6). ${ }^{14}$ En primer lugar, porque mientras que en el resto ha podido entrar sin ningún problema cubriéndose con un velo y el ferâce, en esta ocasión va a necesitar un permiso especial del kaymakan o gobernador civil de la ciudad. Nadie explica por qué era necesario el citado permiso para acceder a Santa Sofía y no para otras mezquitas, ni tampoco hablan de si era un permiso obligado para todos los no musulmanes, solo para los cristianos, o específico para los extranjeros. Lady Mary opina que se debe a que los otomanos temen que los cristianos puedan profanar el templo yendo a rezar a los santos que aún pueden verse en sus paredes. Y esto enlaza con otro de sus comentarios: la mezquita contiene todavía algunos mosaicos bizantinos que no han sido tapados ni desfigurados por los turcos, a pesar de lo que muchos occidentales sostienen. Aunque su afirmación de que ha visitado en su interior la tumba del emperador Constantino es imposible ya que esa tumba nunca estuvo allí. ${ }^{15}$

\subsection{La inoculación contra la viruela}

En la carta XXXII Lady Montagu explica a su amiga Sarah Chiswell cómo se combate esta enfermedad entre los turcos: las ancianas de cada localidad realizan cada año injertos en la piel de personas sanas con agujas impregnadas en pus de algún enfermo de viruela (118-9) consiguiendo así la inmunidad de los inoculados. Este sistema era de origen antiguo y probablemente llegó a Oriente Medio desde China (donde se aplicaba desde al menos el siglo x). Lady Mary queda asombrada y, a partir de ese mismo momento, decide importarlo a su país. De hecho, no solo inoculó a sus hijos, sino que, a su vuelta a Inglaterra, se convirtió en una abanderada de la «variolización» comenzando una fuerte campaña a su favor que resultó muy polémica. En realidad, era un método peligroso ya que la persona inoculada podía enfermar y morir con facilidad si la cepa elegida para impregnar la aguja era muy reciente. Además, podía contraer otra enfermedad padecida por el donante (como la sífilis, por ejemplo).

El asunto de la viruela es un tema poco tratado o simplemente citado (Kaçmaz y Çoban Döşkaya 2018: 26) en los artículos de Ciencias Sociales, aunque sí aparece con cierta frecuencia en los de Medicina y en los de divulgación. Resulta, con todo, muy interesante una observación de Barın Akman acerca de la traducción al turco de esta carta. Según ella, aunque lady Montagu dice claramente que las personas que se ocupan habitualmente de hacer la inoculación son mujeres ancianas, desde la primera traducción al turco la palabra «mujeres»

\footnotetext{
${ }^{14}$ La basílica edificada por el emperador bizantino Justiniano fue reconvertida en mezquita tras la conquista otomana de Constantinopla en 1453.

${ }^{15}$ Parece ser que la tumba del citado emperador estuvo en la primera iglesia de los Santos Apóstoles (edificada por orden de Constantino el Grande entre 335-9, aunque derribada por el emperador Justiniano para levantar en su lugar una basílica mayor), desaparecida en la actualidad. En el solar donde se encontraba fue construida la mezquita imperial de Fatih.
} 
fue sustituida por «personas». En su opinión esto ha privado a los lectores turcos de valorar el papel que las ancianas tuvieron en la sanidad en épocas antiguas (2021: 451).

Por otra parte, el académico Murat Belge (2005: 349) dice que el asombro de lady Montagu por la inoculación es utilizado por muchos turcos de forma chovinista para apoyar la existencia de un progreso científico entre los otomanos que en realidad no era tal. El hecho de que la inoculación fuera relativamente efectiva contra la enfermedad no significa que influyera en el desarrollo de la verdadera vacuna. Ya que la vacuna de Edward Jenner (1749-1823), que comenzó a funcionar a partir de 1798, carece de relación con el procedimiento utilizado por los otomanos.

\section{Otros temas}

En las Cartas hay otros aspectos que son poco o nada tratados por los investigadores turcos modernos. Kaplan (2008: 62), por ejemplo, cree que, aparte de la inoculación, existen algunos otros motivos en las Cartas de los que los turcos podrían sentirse también orgullosos y que, por el contrario, no suelen ser citados en ningún artículo, como el asunto de las adopciones de niños de familias pobres por parte de notables sin herederos (XLVIII, 187), costumbre extendida tanto entre los musulmanes como entre otras minorías. Lady Montagu ve esta costumbre muy positiva, aunque añade que algunos padres sin posibles se niegan a entregar a sus hijos. Otro motivo de orgullo serían los comentarios acerca del Derecho Islámico (XXXIX, 152), que lady Mary considera mejor diseñado y más efectivo en algunos aspectos que el inglés (como en las penas impuestas a los mentirosos) (Kaplan 2008: 196). De hecho, otra de las campañas que lady Montagu inició tras su vuelta a Inglaterra, y de la que ningún académico turco habla, fue para que se reformaran las leyes inglesas de divorcio y se aceptara que las mujeres pudieran conservar su dote (Warnock Fernea 1981: 336), una idea que muy posiblemente tomó de su estancia en el Imperio Otomano (XXX, 107).

Llama la atención que no haya casi comentarios (İnan 2017: 6) a las numerosas alusiones a la Antigüedad clásica, tanto en lo que se refiere a lugares, como a monumentos o costumbres. Así, por ejemplo, cuando lady Mary habla de la forma en que los jóvenes disfrutan del campo parece evocar una escena pastoril propia de la antigua Grecia (XXXI, 109-10); o cuando explica el placer con el que está releyendo a Homero y cómo siente que entiende mejor algunos de sus pasajes al estar allí (XXXI, 110-1). También acostumbra a comparar muchas de las situaciones que se le plantean con escenas de libros antiguos: las damas pasan su tiempo en los telares rodeadas de doncellas como seguramente hicieron Andrómaca y Helena (XXXI, 111); el velo que cubría el rostro de Helena debía ser como el que llevan las otomanas (XXXI, 111); el cinturón de Menelao tuvo que ser como el que llevan los notables (XXXI, 111); el recibimiento de una novia es 
como el epitalamio de Helena descrito por Teócrito (XLVIII, 183); etc. Lady Montagu llegó al Imperio Otomano con un bagaje importante de lecturas clásicas y era inevitable que intentara ver en esas tierras una semejanza con lo que había leído. Es probable que el desinterés de los académicos se deba a que no se considera un elemento «turco»y, por tanto, no ven necesario hablar de él. Por otra parte, tampoco se comenta su decepción ante la escasez de restos clásicos, el desconocimiento de la población local del valor que estos poseen o el mal estado en que se encuentran (XXVIII, 97-8: L, 195-200).

$Y$, tal vez porque solo se ocupan de las cartas en el Imperio Otomano, no hay ninguna reseña de la $n^{o} \mathrm{~L}$, escrita en Túnez, muy interesante ya que en ella lady Montagu habla de su viaje de vuelta a Europa pasando por los Dardanelos, Troya, las islas de Mitilene, Lesbos, Quíos y Grecia. En todos esos lugares realiza visitas a distintos monumentos siempre que puede y da su opinión sobre lo que encuentra. Su gran interés por la arquitectura (XXXIII, 122-4; XXXV, 136-7; XLVI, 174-8; XLIX, 190-2), la historia (XXIII, 75-9; XXIV, 81-4; XXXV, 131-4; XLVIII, 182; XLIX, 190), la organización social (XXVIII, 94; XXXV, 133; XLVI, 173-4; XLVIII, 187-9) o las tierras del país (XXVI, 88-9; XXXVI, 139-41; L, 194-8) quedan asimismo sin reseñar. Si acaso se habla de algunos de estos temas solo de pasada y enfocándose en aspectos anecdóticos.

Las explicaciones de lady Montagu acerca de las minorías del Imperio (judíos, griegos, armenios, etc.), su religión, sus formas de vida y costumbres, son en general evitadas, con la excepción de Çolak (2010: 398-401). Pero también se aprecia que no hay un profundo análisis de su aproximación ilustrada a la religión musulmana, que la lleva a hablar del Islam de una forma abierta y tolerante, muestra del interés y el acercamiento que estaba imponiéndose en muchos países europeos. La mayoría de los elementos no elogiosos quedan en el aire, a excepción del problema de los jenízaros y algunos puntos concretos relativos a las mujeres.

Muy pocos valoran el inmenso esfuerzo que lady Montagu tuvo que hacer para entender, aunque solo fuera en parte, la vida en el Imperio. Como ella misma dice, el número de extranjeros que tenían la voluntad de intentarlo era escaso, pues normalmente se limitaban a vivir en la zona de Pera entre las minorías, los comerciantes y otros europeos. Casi ninguno visitaba la parte de la ciudad en la que vivían los turcos musulmanes (lo que hoy denominamos la península histórica de Estambul). Mucho menos entraban en sus casas o se interesaban por sus costumbres (XLVI, 173). Ella, además, se había preocupado por informarse antes de llegar (aunque de poco le sirviera luego) y, desde el principio, se preocupó por aprender la lengua turca. A juzgar por muchos de los comentarios que hace al respecto, no debió de alcanzar mal nivel: pocos meses después de su llegada era capaz de manejarse sin intérprete y de entender textos literarios. Las cartas en las que habla de la poesía clásica otomana (XXXI, 112-6), o trascribe una misiva amorosa (XLII, 166-8) o cuando explica que el turco coloquial es muy diferente al de la corte (XXXI, 111) dan constancia de ello. 
También estudia su historia, literatura, religión... «estoy muy adelantada en mis conocimientos orientales $\mathrm{y}$, a decir verdad, estudio con mucha dedicación» (XXXI, 117).

Baktır (2016) elogia sus conocimientos lingüísticos y su capacidad para traducir poemas intentado conservar no solo el sentido semántico sino también el ritmo y el estilo (pp. 23-4); pero la mayoría de los académicos parecen pensar que esa relativa inmersión era necesaria para entender el país sin pararse a reflexionar que podía no haberlo hecho o pensar en lo difícil que debió resultarle. Se limitan a recalcar que lady Montagu pudo acceder a muchos lugares vetados a otros extranjeros por su calidad de mujer de alto rango y por vestirse según las costumbres de las damas de la nobleza otomana. No obstante, a menudo les molesta que lady Mary haga comparaciones con elementos ajenos a su cultura porque lo ven un rasgo orientalista, sin entender que ella lo hacía para que sus interlocutores comprendieran mejor lo que contaba, ya que necesitaban puntos de referencia. Parecen sentir que hacer analogías con costumbres u obras literarias europeas es una forma de desvirtuar la autenticidad de lo que cuenta. Algunos creen que lady Montagu pasa a veces de un extremo al otro del péndulo orientalista: en lugar de repetir los tópicos de los viajeros anteriores en los que el Imperio y sus habitantes eran vistos de forma negativa, idealiza la realidad otomana de la época, lo cual, hasta cierto punto, también era una falsedad (İnan 2017: 5).

\section{CONCLUSIÓN}

cazar perdices los lunes, leer inglés los martes, estudiar turco los miércoles -en el cual soy ya bastante experta-, dedicarme a los autores clásicos los jueves, escribir los viernes, coser los sábados y recibir visitas y escuchar música los domingos es una manera bastante mejor de que disponer la semana que pasar los lunes en el Salón, los martes en casa de lady Monhun, los miércoles en la ópera, los jueves en el teatro, los viernes en casa de la señora Chetwynd, etc. (bosque de Belgrado, alrededores de Estambul, XXXVII, 145).

Este resumen dirigido al escritor Alexander Pope de sus actividades semanales en una finca estival a las afueras de Estambul puesto en contraste con lo que hacía habitualmente mientras estaba en Londres, nos da una idea de la vida que llevó lady Montagu en el Imperio y de lo inmensamente agradable que le resultó su estancia allí. Sus intentos por entender ese mundo nuevo y asimilar toda la información posible son siempre elogiados por los turcos. Pero el análisis que realizan de las Cartas se concentra solo en determinados puntos, dejando de lado el resto de los elementos que se incluyen. Esos puntos son inevitablemente repetidos con pocas variantes por la mayoría de los académicos: las mujeres, sus costumbres y su «libertad», la ropa y la decoración, el hamam, los jenízaros, etc. De la misma manera, quedan también fuera de cualquier análisis otras etapas del viaje de ida y vuelta al Imperio. Abundan los artículos que se limitan a parafrasear o citar numerosos párrafos de las Cartas, sin añadir explicaciones. Y 
resulta muy difícil encontrar buenos análisis que cotejen las informaciones ofrecidas por lady Montagu con fuentes otomanas de la misma época.

\section{BIBLIOGRAFÍA}

BAKTIR, H. (2007), Representation of the Ottoman Orient in Eighteenth Century English Literature, Tesis de Doctorado (sin publicar), Ankara, School of Social Sciences of Middle East Technical University.

BAKTIR, H. (2016), «Lady Montagu'nün Türkiye Mektupları'na Etnografik bir Bakış», Kare Dergi, 1(1), 13-26.

BARIN AKMAN, F. (2021), «Yabancı Seyyahların Gözünden İstanbul Kadın», en Osmanlı İstanbul'unda Kadın, Özkarabekir, C. (coord.), Estambul, İstanbul Büyükşehir Belediyesi Kültür Yayınları, 435-452.

BAYSAL, A. (2009), «Batılılar Gözüyle Harem: Gerçek ve Fantezi», Turkish Studies, 4(1-I, invierno), 591-603.

Belge, M. (2005), Osmanlı'da Kurumlar ve Kültür, Estambul, Bilgi Üniversitesi Yayınları.

ÇOLAK, S. (2010), «Bir İngiliz Hanımefendisi'nin Lady Montagu Gözüyle Osmanlı Kadını», Mustafa Kemal Üniversitesi Sosyal Bilimler Enstitüsü Dergisi, 7(13), 386-403.

DEMİR, A. (2014), «Lady Montagu'nun Mektupları» [en línea]. Erciyes, Yeniden Ergenekon, 29 de mayo de 2014 [consulta: 01.03.2021]. Disponible en: $<$ https://yenidenergenekon.com/252-lady-montagunun-mektuplari/>.

GÜNDÜZ, N. (2019), «Bir Kadın Seyyahın Kaleminden Osmanlı'da 18. Yüzyıl Saraylı Kadın Erkek Giysileri: Bir Kültür Tanımak», Millî Folklor, 31(124), 121-135.

İNAN, D. (2017), «Montagu, Craven ve Barkley'in Osmanlı Devleti ve Türkler Hakkındaki İzlenimleri», Selçuk Üniversitesi Sosyal Bilimler Enstitüsü Dergisi, 37, $1-11$.

KAÇMAZ, E. y Çoban Döşkaya, F. (2018), «Letters from and to Lady Mary Wortley Montagu», Çă̆daş Türkiye Tarihi Araştırmaları Dergisi, XVII(35, otoño), 23-37.

KAPLAN, S. (2008), «Lady Mary Montegue [sic]. A Lady Traveller's Impressions of the Ottoman Realm and İstanbul (1717)», en İstanbul in the Eyes of Western Travellers, Kaplan, S. (ed.), Estambul, İstanbul Büyükşehir Belediyesi Kültür Yayınları, 55-65.

MontaGU, lady M. (1970 [1768]), Türkiye Mektupları (1717-1718): Tercüman 1011 Temel Eser Estambul, Kervan Kitapçılık. (trad. A. Kurutluoğlu, Turkish Embassy Letters, 1763)

MuRPHY, D. (1988) «Introduction», en Embassy to Constantinople. The Travels of Lady Mary Wortley Montagu, Wortley Montagu, lady M., Londres, Century Hutchinson, 7-37.

OĞUZHAN BÖREKCİ, Ü. A. (2013) «XVIII. Yüzyıl Osmanlı Hayatına İlişkin bir Kadın Seyyahın Tespitleri», Türk Yurdu, 33(310, junio), 190-197.

ÖZAKINCI, C. (2014) «1720'de Türkiye' den İngiltere'ye Götürülen Buluş: Çiçek Aşısı» [en línea]. Turquía: Bütün Dünya, mayo de 2014 [Consulta: 01.03.2021]. Disponible en: $<$ https://www.guncelmeydan.com/pano/1720-de-turkiye-den-ingiltere-yegoturulen-bulus-cicek-asisi-cengiz-ozakinci-t37259.html>.

UMUNÇ, H. (1986), «Batılılar Gözüyle Türkler ve Türkiye: Tarih İçinde Bir Değerlendirme», Türk Dili, 51(414), 417-439.

UMUNÇ, H. (2013), «Doğu ve Ötekilik: İngiliz Seyahatnamelerinde Türk Kimliği (Lady Montagu ve Richard Chandler)», Bilig, 55 (verano), 297-314. 
WARNOCK FERNEA, E. (1981), «An Early Ethnographer of Middle Eastern Women: Lady Mary Wortley Montagu (1689-1762)», Journal of Near Eastern Studies, 40(4), 329-338. Wortley MONTAGU, lady M. (1988 [1763]) Embassy to Constantinople. The Travels of Lady Mary Wortley Montagu, Londres, Century Hutchinson,.

Wortley Montagu, lady M. (2017), Cartas desde Estambul Madrid, La Línea del Horizonte Ediciones. (trad. C. de Filipetto, Turkish Embassy Letters, 1763). 